\title{
ANALISA KINERJA SIMPANG TAK BERSINYAL JALAN SIMPANG BRANGGAHAN NGADILUWIH KABUPATEN
}

\author{
Aditya Yayang Nurkafi *1, Yosef Cahyo $\mathrm{SP}^{2}$, Sigit Winarto ${ }^{3}$, Agata Iwan Candra ${ }^{4}$. \\ ${ }^{1}$ Fakultas Teknik, Universitas Kadiri. \\ e-mail:*1 aditya.nurkafi6@gmail.com, ${ }^{2}$ yosef.cs@unik-kediri.ac.id, ${ }^{3}$ sigit.winarto@unik- \\ kediri.ac.id, ${ }^{4}$ iwan candra@unik-kediri.ac.id.
}

\begin{abstract}
The development of transportation in the Kediri Regency has an impact on increasing people's daily activities in the transportation sector. So far, the Branggahan Ngadiluwih road section at the crossroads leading to the connecting bridge between Ngadiluwih sub-district and Mojo sub-district, at certain hours, there is often traffic activity due to road performance, which plays an important role in transportation activities. This study aims to determine: the value of capacity $(C)$, degree of saturation (DS), the queue of opportunity $(Q P)$, and the value of traffic delay $(D T)$ at the intersection. The method used is data collection based on the MKJI 1997. Based on the results of research and discussion of the performance of the Branggahan Ngadiluwih intersection, the value of the queuing opportunity is between $52.287 \%$ $105.135 \%$, the average value of the delay in traffic exceeds $15 \mathrm{sec} / \mathrm{SMP}$, the value of degrees saturation exceeds the standard, namely 1.136. To reduce the delay that occurs at the intersection. That exceeds the maximum value (> $15 \mathrm{sec} / \mathrm{SMP}$ ), it is necessary to install a parking restriction and stop at an approach where there is no shoulder for parking, and a traffic light is needed.
\end{abstract}

Keywords : Unmarked Intersection, Capacity, Degree Of Saturation, Transportation

\begin{abstract}
Abstrak
Perkembangan transportasi dikabupaten kediri berdampak pada meningkatnya aktivitas keseharian masyarakat di bidang transportasi. Sejauh ini pada ruas jalan branggahan ngadiluwih di simpang jalan menuju jembatan penghubung antara kecamatan ngadiluwih dengan kecamatan mojo pada jam tertentu sering terjadi kesibukan lalu lintas karena kinerja jalan yang menjadi peranan penting dalam kegiatan transportasi. Penelitian ini bertujuan mengetahui: nilai kapasitas (C), derajat kejenuhan (DS), antrian peluang (QP) serta nilai tundaan lalu lintas (DT) pada persimpangan tersebut. Metode yang digunakan adalah pengumpulan data yang berpedoman pada MKJI 1997. Berdasarkan hasil penelitian dan pembahasan kinerja simpang Branggahan Ngadiluwih memiliki nilai peluang antrian disimpang tersebut antara 52,287\% - 105,135\%, nilai tundaan pada lalu lintas rata-rata melebihi $15 \mathrm{det} / \mathrm{smp}$, nilai derajat kejenuhan melebihi standart yaitu 1,136 . Untuk menurunkan tundaan pada simpang yang melebihi nilai maksimum (>15 det/smp) besarnya perlu dipasang larangan parkir dan berhenti di pendekat yang tidak tersedia bahu untuk parkir serta perlu pemasangan lampu lalu lintas (Traffic Light).
\end{abstract}

Kata Kunci : $\quad$ Simpang Tak Bersinyal, Kapasitas, Derajat Kejenuhan, Transportasi 


\section{PENDAHULUAN}

Pertambahan jumlah kendaraan yang tidak diimbangi dengan perkembangan prasarana akan menimbulkan konflik pada jalan khususnya di persimpangan atau bundaran [1][2][3]. Sejauh ini pada ruas Jalan Branggahan Ngadiluwih menuju jembatan penghubung antara Kecamatan Ngadiluwih dan Mojo pada jam tertentu sering terjadi kesibukan lalu lintas yang tidak efektif dengan kinerja jalan yang menjadi peranan penting dalam transportasi [4][5][6].

Simpang empat jalan Branggahan adalah pertemuan ruas jalan diantaranya Jl.Raya Kras ke Kota Tulung Agung, Jl. Branggahan, Jl. Puskesmas dan Jl. Merak. Simpang ini merupakan jalan Kabupaten yang menuju atau dari pusat Kota Kediri yang dimana pada jam-jam tertentu sering terjadi tundaan dan antrian kendaraan walaupun disisi jalan persimpangan tersebut sudah ada relawan warga untuk mengatur lalu lintas, karena kawasan ini termasuk daerah pertokoan, pusat arus antar kecamatan diarah jalan menuju jembatan baru penghubung Kecamatan Ngadiluwih dengan Kecamatan Mojo, perkantoran, serta pendidikan sehingga menjadikan arus lalu lintasnya sibuk. Dengan dibangunya jembatan penghubung baru antara Kecamatan Mojo dengan Kecamatan Ngadiluwih membuat simpang empat Branggahan Ngadiluwih ini menjadi pusat pertemuan arus lalu lintas, serta dengan pertemuan pada arus lalu lintas dari pusat kota Kediri dengan kota Tulungagung menjadikan simpang Branggahan tersebut menjadi ramai dengan transportasi antar kota [7][8][9].

Berdasarkan keadaan tersebut maka pada persimpangan jalan Branggahan Ngadiluwih Kabupaten Kediri perlu mendapatkan perhatian cukup dengan memberi prasarana jalan dipersimpangan tersebut agar dapat melayani arus lalu lintas dengan baik serta menghindari konflik dan mengurangi angka kecelakaan yang terjadi di persimpangan tersebut [10].

Sehubungan dengan hal itu maka perlu dilakukan penelitian pada simpang tak bersinyal Simpang Jalan Raya Branggahan Ngadiluwih guna untuk mengetahui kinerja dari simpang tersebut, agar nantinya simpang pada ruas jalan tersebut dapat melayani volume dari arus lalu lintas secara optimal. Sehingga pengguna jalan yang melintas dipersimpangan jalan Raya Branggahan Ngadiluwih akan merasa tetap aman dan nyaman. Penelitian dan analisa ini memiliki tujuan yaitu sebagai berikut [11][12][13].

1. Mengetahui kapasitas (C) arus lalu lintas pada Simpang Branggahan Ngadiluwih Kabupaten Kediri.

2. Mengetahui berapa derajat kejenuhan (DS) pada persimpangan tersebut.

3. Mengetahui sudah layak atau belum Simpang Branggahan Ngadiluwih untuk dipasang Traffic Light.

4. Mengetahui potensi tingkat kemacetan dari nilai analisis tundaan (D) lalu lintas di simpang tersebut. 
5. Mengetahui persentase nilai peluang antrian (QP) di Simpang Branggahan Ngadiluwih.

Untuk menghindari adanya penyimpangan maupun pelebaran pokok masalah, maka diperlukan adanya pembatasan masalah agar penelitian lebih terarah dan memudahkan dalam pembahasan. Beberapa batasan masalah dalam penelitian ini adalah sebagai berikut :

1. Penelitian dilaksanakan disimpang tak bersinyal Jalan Simpang Branggahan Ngadiluwih Kabupaten Kediri.

2. Kinerja dianalisa berdasarkan dari pedoman MKJI 1997.

3. Penelitian dilaksanakan pada jam puncak berdasarkan survei pendahuluan.

4. Kinerja simpang yang dianalisa mencangkup volume, kapasitas, derajat kejenuhan, tundaan lalu lintas dan peluang antrian.

Manfaat yang diperoleh dari penelitian ini adalah sebagai referensi bagi praktisi teknik sipil dalam mengembangkan ilmu dibidang simpang tak bersinyal.

\section{METODE PENELITIAN}

\subsection{Simpang}

Menurut penelitian Lutfi Riyadi yang berjudul "Studi Kinerja Simpang Tak Bersinyal Manahan Atas Dasar Observasi Ekuivalensi Mobil Penumpang" menyimpulkan bahwa "kondisi simpang Manahan pada saat jam sibuk dalam keadaan jenuh karena mempunyai nilai Derajat Kejenuhan (DS) 0,81-3,52 yang artinya melebihi persyaratan dari pedoman MKJI 1997 yaitu nilai tinggi 0,75. Dengan dibuktikan arus lalu lintas pada persimpangan ternyata lebih tinggi dari kapasitas persimpangan pada kondisi yang berkisar antara 2318-8534 smp/jam. Maka persimpangan tersebut perlu dijadikan bundaran dengan pengkajian ulang terlebih dahulu”, [14][15].

\subsection{Simpang Tak Bersinyal}

Simpang tak bersinyal adalah simpang yang tidak memiliki alat pemberi isyarat lampu lalu lintas. Pada umumnya simpang tak bersinyal di pergunakan di daerah permukiman perkotaan serta daerah pedesaan maupun pada daerah pedalaman bagi persimpangan antara jalan lokal ataupun lingkungan yang arus lalu lintasnya cukup rendah. Pada keefektifan simpang tak bersinyal dapat terjadi apabila jika ukuranya kecil serta dengan daerah konflik lalu lintasnya dipilih dengan baik, maka dari itu simpang dua lajur tak terbagi ini sangat sesuai dengan persimpangan tersebut, [16]. Pada persimpangan antara jalan arteri, penutupan daerah konflik bisa terjadi dengan mudahnya yang menyebabkan kinerja arus lalu lintas terputus sementara. Apabila jika perilaku simpang tak bersinyal dalam tundaan rata-ratanya selama periode waktu yang lebih lama lebih rendah dari jenis simpang yang lain, simpang pada jenis ini mungkin masih 
lebih dipilih karena pada suatu kapasitas arus lalu lintas tertentu dapat dipertahankan meskipun dalam kondisi serta keadaan lalu lintas yang berada pada jam puncak.

\subsection{Management Lalu Lintas}

Menurut Alamsyah "Manajemen Lalu Lintas adalah suatu proses pengaturan dan penggunaan sistem jalan raya yang sudah ada dengan tujuan untuk memenuhi suatu tujuan tertentu tanpa perlu penambahan/pembuatan infrastruktur baru. Manajemen lalu lintas diterapkan untuk memecahkan masalah lalu lintas jangka pendek (sebelum pembuatan infrastruktur baru dilaksanakan), atau diterapkan untuk mengantisipasi masalah lalu lintas yang berkaitan (misalnya: kemacetan lalu lintas pada tahap konstruksi, dll)", [17][18].

\subsection{Tipe Lingkungan Jalan}

Suatu jenis jalan pada persimpangan terdapat tipe kondisi yang bermacam-macam dan dapat dibagi serta diklasifikasikan kedalam beberapa jenis kelas menurut analisis dan juga survey lapangan dari tata guna tanah serta aksesibilitas pada ruas jalan tersebut dari aktifitas yang berada disekitarnya. Tipe lingkungan jalan dapat di bagi menjadi 3 klasifikasi kelas yaitu sebagai berikut.

1. Komersial

2. Pemukiman

3. Akses terbatas

\subsection{Volume Lalu Lintas}

Dihitung dengan melakukan survey arus kendaraan total yang melintasi simpang pada tiaptiap ruas jalan (smp/jam) untuk dibuat acuan dalam menghitung kapasitas (C) lalu lintas pada simpang tersebut.

\subsection{Kapasitas $(C)$}

Menurut MKJI 1997 besarnya nilai dari kapasitas (C) dapat dihitung berdasarkan dengan menggunakan formula rumus seperti berikut :

$\mathrm{C}=\mathrm{C}_{\mathrm{o}} \times \mathrm{Fw} \times \mathrm{FM} \times \mathrm{Fcs} \times \mathrm{FRSU}$ X FLT X FRT X FMI

Dengan :

Co $\quad=$ Kapasitas $(\mathrm{smp} / \mathrm{jam})$.

(CO $=2900 \mathrm{smp} / \mathrm{jam} / \mathrm{lajur})$.

FM = Faktor koreksi median jalan utama.

$\mathrm{FW} \quad=$ Faktor penyesuaian lebar masuk.

Formula rumus yang digunakan sebagai berikut ini.

$\mathrm{WI}=(\mathrm{WA}+\mathrm{WC}+\mathrm{WB}+\mathrm{WD})$

Jumlah Lengan pada Simpang

$\mathrm{FW} \quad=0,70+0,0866 \mathrm{~W} 1$ 
Dengan:

WA, WB, WC,WD = lebar rata-rata pendekat ( meter ).

FLT = Faktor penyesuain belok kiri. Menggunakan formula dari rumus berikut ini:

FLT $=0,84+1,61 \times$ PLT

FRT $=$ Faktor penyesuaian belok kanan.

FRT $=1,09-0,922 \times P R T$.

FCS $=$ Faktor penyesuaian ukuran kota.

FRSU $=$ Faktor penyesuaian rasio kendaraan tak bermotor, hambatan samping, tipe jalan serta tipe lingkungan jalan.

FMI $=$ Faktor penyesuaian rasio arus lalu lintas jalan minor

\subsection{Derajat Kejenuhan (DS)}

Derajat kejenuhan (DS) bisa dihitung berdasarkan dengan menggunakan formula rumus yaitu sebagai berikut ini.

$D S=\frac{Q t o t}{C}$

Dengan :

C $\quad$ Kapasitas (smp/jam)

Qtot $=$ Arus total lalu lintas (smp/jam)

Untuk jumlah Derajat Kejenuhan (DS) pada suatu persimpangan menurut pedoman dari MKJI 1997 bisa dikatakan bernilai tinggi yaitu jika derajat kejenuhan lebih dari 0,75 (>0,75) dan dikatakan jenuh jika nilainya melebihi standart dari pedoman MKJI 1997 yaitu 0,75, [19].

\subsection{Tundaan Lalu Lintas $(D)$}

Menurut Alamsyah "tundaan adalah perbedaan waktu perjalanan dari suatu perjalanan dari satu titik ke titik tujuan antara kondisi arus bebas dengan arus terhambat", [20].

Tundaan lalu lintas merupakan suatu tundaan yang terjadi pada persimpang karena adanya beberapa faktor yang mempengaruhi serta dapat dihitung menggunakan rumus yaitu antara lain sebagai berikut ini.

1) Tundaan lalu lintas pada simpang (DT1)

$$
\begin{aligned}
& \text { DT1 }=2+8,2078 \times \text { DS }-(1-D S) \times 2(\text { DS }>0,6) \text {. } \\
& \text { DT1 = 1,0504 /(0,2742-0,2042 x DS)-(1-DS) } 2 \text { (DS>0,6). }
\end{aligned}
$$

2) Tundaan lalu lintas jalan mayor (DTMA)

$$
\begin{aligned}
& \text { DTMA }=1,8+5,8234 \times(1-D S) \times 1,8(\text { DS }<0,6) \ldots \ldots \ldots \ldots \ldots \ldots \ldots \ldots \ldots \ldots \ldots \ldots \ldots \ldots \\
& \text { DTMA }=1,05034 /(0,346-0,246 \times \text { DS })-(1-D S) \times 1,8 \quad(\text { DS }>0,6) .
\end{aligned}
$$

3) Tundaan lalu lintas jalan minor (DTMI)

DTMI $=($ Qtot $\mathrm{x}$ DT1 - QMA $\times$ DTMA $) / Q M I$. 
4) Tundaan geometrik jalan simpang (DG)

$\mathrm{DG}=(1-\mathrm{DS}) \times(\mathrm{PT} \times 6+(1-\mathrm{PT}) \times 3)+\mathrm{DS} \times 4(\mathrm{DS}<1,0)$.

$\mathrm{DG}=4 \quad(\mathrm{DS}>1,0)$

5) Tundaan pada simpang (D)

$\mathrm{D}=\mathrm{DG}+\mathrm{DT} 1$

\subsection{Peluang antrian $(Q P)$}

Jika nilai derajat kejenuhan besar maka nilai persentase peluang antrian juga ikut besar. Peluang antrian dapat dihitung berdasarkan formula rumus berikut ini.

$\mathrm{QP} \%=9,02 \times \mathrm{DS}+20,66 \times \mathrm{DS} 2+10,49 \times \mathrm{DS} 3$ (batas bawah)

$\mathrm{QP} \%=47,71 \times \mathrm{DS}-24,68 \times \mathrm{DS} 2+56,47 \times \mathrm{DS} 3$ (batas atas)

Berdasarkan pedoman dari MKJI 1997 jumlah nilai dari batas bawah adalah 23\% dan untuk nilai batas atas sebesar $45 \%$.

\subsection{Konflik Simpang Tak Bersinyal}

Salah satu alternatif penyelesain permaslahan konflik lalu lintas menurut Tamin adalah Meningkatkan pertumbuhan prasarana transportasi terutama dengan memaksimalkan pemanfaatan prasarana yang ada dan belum berfungsi dengan semestinya. Misalnya dengan membangun jaringan jalan baru atau melebarkan jalan yang sudah ada.

Titik konflik yang terjadi pada suatu simpang dimana disitu terdapat pertemuan antara berbagai macam jenis kendaraan yang melakukan aktivitas pada persimpangan dan menyebabkan suatu konflik arus lalu lintas pada persimpangan.

Dari berbagai macam permasalahan dalam persimpang terdapat juga berbagai macam gerakan yang sangat mempengaruhi kinerja pada suatu simpang yaitu sebagai berikut ini : Gerakan yang memisah, gerakan yang memotong, gerakan seperti jalinan / Anyaman, gerakan yang menyatu.

Konflik tersebut dapat digambarkan sebagai berikut ini

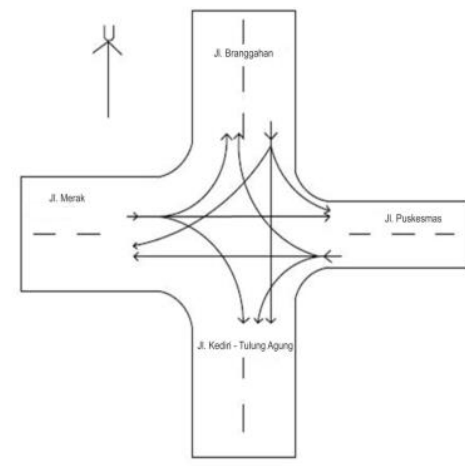

Sumber : Analisa Pengamatan

Gambar 1 Titik Konflik Pada Simpang Branggahan Ngadiluwih. 


\subsection{Desain Penelitian}

Dengan memilih lokasi dan aktivitas kendaraan yang melintasi perismpangan secara visual yaitu komposisi suatu kendaraan, keadaan Geometrik pada jalan simpang, serta fasilitas-fasilitas yang ada di jalan tersebut. Agar pelaksanaan survei dapat berjalan dengan baik dan dapat meminimalkan kesalahan atau hambatan, kegiatan yang dilakukan antara lain: membuat formulir penelitian untuk pencatatan arus kendaraan dan pengujian efektif dari formulir yang digunakan, mengumpulkan sejumlah pengamat, menentukan lokasi pengamat pada suatu pendekat atau lengan, menentukan waktu survei, dan periode pengamatan, mempersiapkan alat-alat penelitian. Selanjutnya melakukan Studi Pustaka dan pendahuluan, literatur yang digunakan bersumber dari buku-buku yang berhubungan dengan simpang dan MKJI tahun 1997. Tujuan dari studi pendahuluan ini adalah untuk menentukan parameter data yang akan disurvei dan juga untukmenentukan metode apa saja yang akan diperlukan untuk mengumpulkan data. Langkah kegiatan yang dilakukan dalam tahapan studi pendahuluan ini meliputi:

1. Perumusan tujuan pengumpulan data.

2. Melakukan studi literatur.

3. Mendefinisikan dan menentukan parameter-parameter yang akan dikaji.

4. Merumuskan dan menentukan lingkup survei.

5. Menentukan metode survei.

Penelitian ini akan dilakukan di Simpang Branggahan yaitu pertemuan ruas jalan Raya Branggahan diarah Utara ke Selatan jalan Raya Kras (Kediri - Tulung Agung) yang termasuk jalan arteri, ruas jalan Merak dari arah Barat yang termasuk jalan kolektor (arah jembatan baru ngadiluwih - mojo) dan ruas jalan Puskesmas dari arah Timur yang termasuk jalan lingkungan. Setelah dilakukannya survei pendahuluan, direncanakan waktu penelitian akan diambil 2 hari dalam durasi waktu satu minggu yaitu pada hari senin dan juga kamis serta dilakukan pada jam puncak arus lalu lintas yaitu untuk pagi pukul 06.30-07.30 dimana pada jam tersebut adalah jam yang dimana masyarakat sekitar melakukan aktivitas berangkat sekolah, berangkat bekerja dan juga memulai aktivitas perdagangan serta untuk jam siang pukul 13.00-14.00 WIB, dimana masyarakat sekitar melakukan aktivitas pulang sekolah, aktivitas kerja dan juga aktivitas perdagangan lainnya. Penelitian juga di lakukan pada jam sore pukul 16.00-17.00 WIB.

\subsection{Pengumpulan Data}

Pengumpulan data dilakukan untuk menganalisa rumusan masalah dan sebagai dasar untuk perhitungan pada standart pedoman. Teknik analisa yang akan dilakukan adalah dengan cara mengumpulkan data sekunder yaitu data yang dibutuhkan untuk mendukung analisa perhitungan dan juga mengumpulkan data primer. 
Berbagai data yang diperlukan dalam melakukan penelitian ini diantaranya sebagai berikut ini

\section{Data Primer (Utama)}

Data-data primer (utama) yaitu data yang diambil langsung dari lapangan diantaranya kondisi geometrik, kondisi lingkungan, hambatan samping, jenis kendaraan. Pengumpulan data primer sebagai berikut.

1. Kapasitas Simpang

2. Volume lalu lintas

3. Derajat Kejenuhan

4. Tundaan

5. Peluang antrian

Ada beberapa alat pendukung yang perlu disiapkan sebelum melakukan survey guna untuk mendukung pelaksanaan di lapangan yaitu sebagai berikut.

1. Formulir Survei, yaitu berguna sebagai pedoman untuk mencatat apa saja yang perlu dicatat dari aktivitas kendareaan diberbagai ruas jalan yang sedang diteliti.

2 Alat Tulis, yaitu berguna untuk mencatat hasil pengamatan dilapangan kedalam formulir survey.

3 Jam (ukur waktu), yaitu berguna untuk menentukan waktu penelitian pada arus lalu lintas yang akan diteliti.

4 Roll Meter (alat ukur), yaitu alat yang berguna untuk mengukur lebar jalan.

2. Data Sekunder

Merupakan data yang diambil untuk bahan pendukung dalam penelitian sebagai acuan untuk menganalisis data. Data yg diambil adalah dari Dinas Kependudukan dan Catatan Sipil Kabupaten Kediri untuk mengetahui jumlah penduduk.

\subsection{Analisis Data}

Dalam penelitian studi kasus ini kinerja simpang yang akan diteliti adalah kapasitas (C), nilai derajat kejenuhan (DS) serta tundaan simpang (D) serta jumlah nilai persentase dari peluang antrian (QP). Untuk melakukan analisis perhitungan derajat kejenuhan variabel yang diperlukan adalah nilai arus total dan nilai kapasitas jalan. Didalam perhitungan untuk menentukan derajat kejenuhan dapat dilakukan dengan membagi arus total pada simpang dengan kapasitas simpang.

Langkah-langkah dalam menganalisa data-data dalam penelitian ini yaitu melakukan pembelajaran tema dan topik penelitian, selanjutnya menganalisa penguraian data jenis kendaraan dan volume kendaraan, serta menganalisa waktu pelaksanaan dan juga melakukan perhitungan data-data yang didapatkan dari hasil survei penelitian dilapangan, lalu melakukan pembahasan 
tentang hasil perhitungan yang telah dilakukan dan memberikan kesimpulan untuk pengambilan keputusan.

\subsection{Bagan Alir Penelitian}

Bagan Alir Penelitian (Flowchart) adalah bagan (chart) yang menunjukan alir (flow) di dalam program atau prosedur sistem penelitian secara logika dimana setiap jalur kegiatan dalam penelitian dapat tertulis, terencana dan juga terperinci dengan jelas dalam sebuah alur penelitian yang nantinya alur tersebut dapat menjadikan pedoman penelitian bagi penulis untuk meneliti sebuah kasus tertentu seperti gambar 2 sebagai berikut.

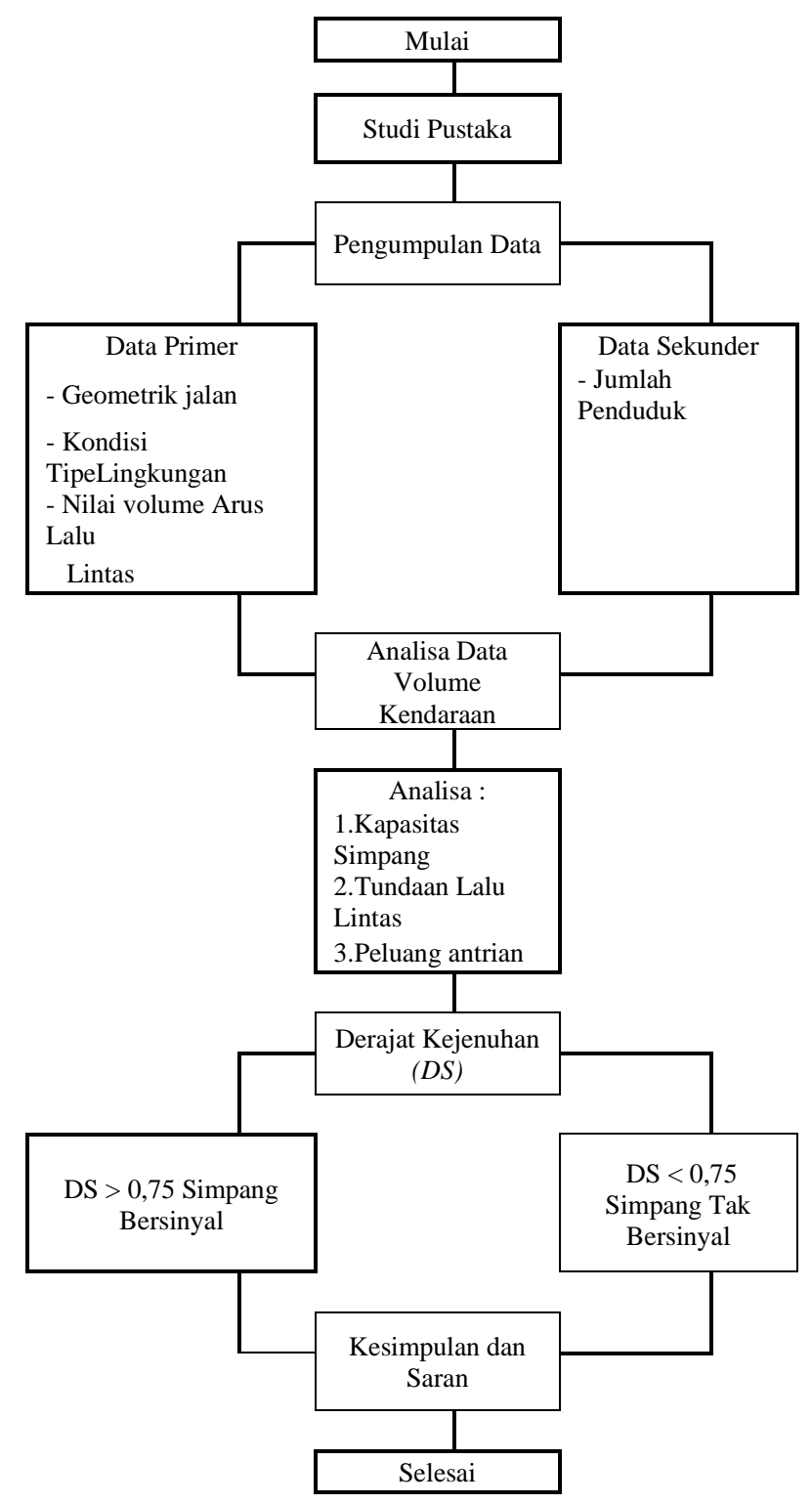

Sumber : Analisa Pengamatan

Gambar 2 Bagan Alur Penelitian 


\section{HASIL DAN PEMBAHASAN}

\subsection{Deskripsi Data}

Penelitian dilaksanakan pada Simpang empat Branggahan Ngadiluwih yaitu pertemuan dari Jl. Raya Branggahan - Jl. Raya Kras (Kediri - Tulung Agung) dan Jl. Puskesmas - Jl. Merak. Analisa penelitian dilakukan dengan cara mengambil beberapa data antara lain kendaraan bermotor Motorcycle (MC), kendaraan ringan Light vehicle $(L V)$, serta kendaraan berat Heavy vehicle $(H V)$. Pengambilan data tersebut dilakukan secara bersamaan pada tiap-tiap ruas jalan di masing - masing lokasi simpang selama jam puncak pagi jam 06.30-07.30 WIB dimana banyak warga sekitar dan pengguna jalan banyak melakukan aktivitas transportasi, siang 13.00-14.00 WIB, dan serta pada jam puncak arus lalu lintas sore 16.00-17.00 WIB. Berdasarkan survei yang dilakukan dilapangan dapat diperoleh sampel data yang akan di gunakan berupa jumlah volume arus kendaraan pada simpang. Data yang dipakai untuk menganalisa dalam penelitian ini yaitu data-data jumlah volume arus lalu lintas paling puncak dalam satuan mobil penumpang dibagi satu jam (smp/jam), setelah didapat data dari survei dilapangan pada jam puncak. Data yang dipakai dari perhitungan survei di lapangan digunakan volume kendaraanya paling puncak yaitu data volume kendaraan pada hari kamis jam puncak siang yang berada pada jam 13.00-14.00 WIB dimana banyak transportasi kendaraan berat yang melintas. Dari hasil penelitian di lapangan kendaraan yang melintas sebagian besar terdiri dari kendaraan roda dua yaitu sepeda motor (motorcycle).

\subsection{Volume Kendaraan}

Jumlah dari nilai volume kendaraan sangat bergantung pada jenis jalan yang terdapat pada persimpangan. Dalam menganalisa volume kendaraan yang diperoleh dari hasil penelitian di lapangan dibagi menjadi 2 yaitu volume arus total (Qtot) dan volume arus lalu Jalan mayor (QMA) serta jalan minor (QMI). Dari hasil tinjauan arus lalu lintas LV (Tipe Kendaraan Ringan) adalah 1626 smp/jam, MC (Tipe Kendaraan Sepeda Motor) 1025,5 smp/jam, HV (Tipe Kendaraan Berat) 1383,2 smp/jam total arus lalu lintas (Qtot) adalah 4034,7 smp/jam, pada jalan mayor (QMA) 2851,1 smp/jam serta arus pada minor (QMI) adalah 1183,6 smp/jam.

\subsection{Analisis Data.}

Dalam menganalisis Simpang Branggahan Ngadiluwih dapat dilakukan dengan cara memadukan data-data yang diperoleh dan dengan menggunakan formula rumus yang terdapat pada pedoman standart dari MKJI 1997 sehingga simpang tersebut dapat dihitung guna mencari data yang diharapkan. Analisis yang dilakukan dari berbagai macam data variable masukan yang sudah ditemukan guna untuk mencari jumlah kapasitas arus lalu lintas simpang pada simpang tak bersinyal di Simpang Jalan Branggahan Ngadiluwih yaitu sebagai berikut ini. 


\section{Kapasitas (C)}

Dibutuhkan selain kapasitas dasar juga dibutuhkan beberapa faktor-faktor pendukung yaitu meliputi sebagai berikut ini.

1. Kapasitas dasar $(\mathrm{Co})=2900 \mathrm{smp} / \mathrm{jam}$.

2. Faktor penyesuaian lebar pendekat $(\mathrm{Fw})$ ditentukan dengan mengetahui terlebih dahulu lebar pendekat yang tergambar pada Gambar 3 yaitu sebagai berikut ini.

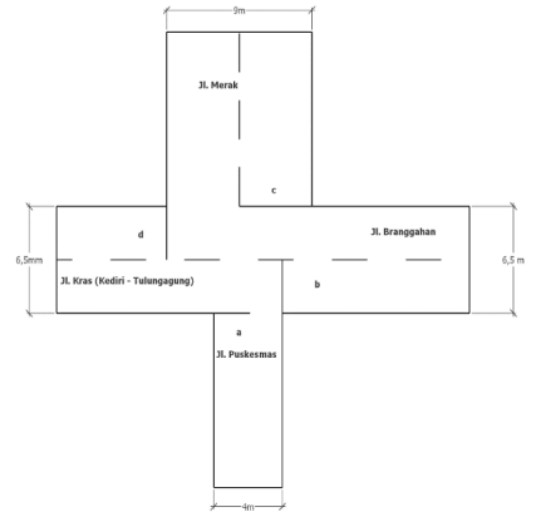

Sumber : Analisa Pengamatan

Gambar 3. Lebar Rata-rata Pendekat Simpang.

Lebar pendekat $\mathbf{d}$ hanya untuk keluar, maka kode $\mathbf{d}$ adalah 0 ( menjadi 3 legan pada simpang )

$W_{1}=\frac{W a+W b+W c+W d}{\text { Jumlah lengan panda simpang }}$

$W_{1}=\frac{2+3,25+4,5+3,25}{3}$

$\mathrm{Fw}=0,70+0,0866 \mathrm{x} \mathrm{WI}$

$\mathrm{FW}=0,70+0,0866 \times 4,333=1,075267$

1. Faktor penyesuaian median jalan utama (FM) didapatkan dari standart pedoman dari MKJI 1997 dengan jumlah nilai $\mathrm{FM}=1,2$.

2. Jumlah penduduk dikota Kediri akhir tahun 2018 dengan jumlah 1.568.113 jiwa. Maka nilai $\mathrm{Fcs}=1$.

3. Rasio kendaraan tak bermotor $(\mathrm{PUM})=0,0302$, maka jumlah nilai dari FRSU adalah 0,93. $\mathrm{PUM}=\mathrm{QUM}($ kendaraan/jam) $/$ Qtot (kendaraan/jam)

$\mathrm{PUM}=143 / 4741=0,0302$

4. $\mathrm{PLT}=\mathrm{QLT}(\mathrm{smp} / \mathrm{jam}) /$ Qtot $(\mathrm{smp} / \mathrm{jam})$

PLT $=967,8 / 4034,7=0,2399$

Maka FLT $=\{(0,84+(1,61 \times$ PLT $)\}$

FLT $=\{(0,84+(1,61 \times 0,02399)\}=1,2262$ 
5. $\quad$ PRT $=908,7 / 4034,7=0,2252$

Maka FRT $=1,09-0.922 \times$ PRT

$\mathrm{FRT}=1,09-0.922 \times 0,2252=0,8823$

6. Faktor penyesuaian rasio untuk arus lalu jalan minor (FMI).

$\mathrm{PMI}=\mathrm{QMI} / \mathrm{Q}$ tot

$\mathrm{PMI}=1183,6 / 4034,7=0,2934$.

Pada persimpangan Branggahan Ngadiluwih tersebut termasuk dalam kategori tipe simpang 422. Jadi rumusnya adalah.

$$
\begin{aligned}
\text { FMI } & =1,19 \times \text { PMI }-1,19 \times \text { PMI }+1,19 \\
& =1,19 \times 0,29342-1,19 \times 0,2934+1,19 \\
& =0,9433
\end{aligned}
$$

Dengan didapatnya jumlah nilai dari variabel yang diperlukan maka

$$
\begin{aligned}
\text { C } & =\{\text { Co } \times \text { Fw } x \text { FCS } \times \text { FM } \times \text { FRSU } \times \text { FLT } \times \text { FRT x FMI }\} \\
& =\{2900 \times 1,2 \times 1,075267 \times 1 \times 0,93 \times 1,22619 \times 0,8823461 \times 0,9433155\} \\
& =3551,66351 \mathrm{smp} / \mathrm{jam}
\end{aligned}
$$

Derajat Kejenuhan (DS)

$\mathrm{DS}=\frac{4034,7 \mathrm{smp} / \mathrm{jam}}{3551,6635 \mathrm{smp} / \mathrm{jam}}$

$\mathrm{DS}=1,136$

Tundaan Lalu Lintas Simpang ( $\left.\mathrm{DT}_{1}\right)$

Nilai derajat kejenuhan melebihi 0,60 (DS>0,60) yaitu dengan jumlah nilai 1,136 maka.

DT1 $=1,0504 /(0,2742-0,2042 \times 1,136)-(1-1,136) \times 2$

DT1 $=25,1464 \operatorname{det} / \mathrm{smp}$

Tundaan Lalu Lintas Jalan Mayor (DT $\left.\mathrm{DA}_{\mathrm{MA}}\right)$

$\mathrm{DT}_{\mathrm{MA}}=1,05034 /(0,346-0,246 \times 1,136)-(1-1,136) \times 1,8$

$\mathrm{DT}_{\mathrm{MA}}=16,0291 \mathrm{det} / \mathrm{smp}$

Tundaaan Lalu Lintas Jalan Minor (DT $\mathrm{MI})$

$\mathrm{DT}_{\mathrm{MI}}=\left(\mathrm{Q}\right.$ tot $\left.\times \mathrm{DT}_{1}-\mathrm{Q}_{\mathrm{MA}} \times \mathrm{DT}_{\mathrm{MA}}\right) / \mathrm{Q}_{\mathrm{MI}}$

$\mathrm{DT}_{\mathrm{MI}}=(4034,7 \times 25,1464-2851,1 \times 16,0291\} / 16,0291$

DTMI $=47,1084 \mathrm{det} / \mathrm{smp}$

Tundaan Geometrik Simpang (DG)

Berdasarkan dari pedoman MKJI 1997 nilai Derajat Kejenuhan (DS) sebesar 1,136 maka DG = 4 detik/smp.

Tundaan Simpang (D) 
$\mathrm{D}=(4+25,1464)$

$\mathrm{D}=29,1464 \mathrm{det} / \mathrm{smp}$

Peluang Antrian (QP)

$\mathrm{QP} \%=\{(47,71 \times 1,136-24,68 \times 1,1362+56,47 \times 1,1363)\}=105,135 \%$ (Batas atas).

$\mathrm{QP} \%=\{(9,02 \times 1,136)+(20,66 \times 1,1362)+(10,49 \times 1,1363)\}=52,287 \%$ (Batas bawah)

\section{KESIMPULAN}

Dari hasil pengujian yang didapat dapat ditarik kesimpulan yang dapat disajikan dengan sebagai berikut :

Setelah dilakukannya perhitungan dan pembahasan oleh peneliti, maka dalam penelitian ini dapat diambil kesimpulan yaitu sebagai berikut.

1. Arus lalu lintas kendaraan total (Qtot) pada jam puncak sebesar $4034,7 \mathrm{smp} / \mathrm{jam}$ atau lebih dari kapasitas simpang sebenarnya sebesar 3551,66 smp/jam. Maka kinerja dari simpang Branggahan perlu dioptimalkan.

2. Derajat Kejenuhan memiliki nilai lebih dari 0,75 (DS) $>0,75$ yaitu 1,136 maka simpang Branggahan Ngadiluwih ini mempunyai tingkat pelayanan lalu lintas cukup jenuh.

3. Derajat Kejenuhan lebih dari batas standart 0,75 yaitu 1,136 maka simpang ini perlu dipasang lampu lalu lintas (Traffic Light ) pada persimpangan tersebut.

4. Tundaan Lalu Lintas (D) dapat dibagi menjadi lima jenis tundaan lalu lintas yaitu meliputi sebagai berikut.

1. Tundaan Lalu Lintas Simpang (DTI) kurang stabil dengan nilai yaitu sebesar 25,1464 det/smp yang lebih dari standart yaitu sebesar $15 \mathrm{det} / \mathrm{smp}$.

2. Tundaan Lalu Lintas Jalan Mayor (DTMA) tidak stabil karena mempunyai nilai yaitu 16,0291 det/smp dan lebih dari standart yang telah ditentukan yaitu $15 \mathrm{det} / \mathrm{smp}$.

3. Tundaan Lalu Lintas Jalan Minor (DTMI) tidak stabil karena nilainya 47,1084 det/smp dan lebih dari $15 \mathrm{det} / \mathrm{smp}$.

4. Sesuai pedoman dari standart MKJI 1997 Tundaan Geometrik Simpang (DG) $=4$ $\operatorname{det} /$ smp.

5. Tundaan Simpang (D) disimpang ini belum stabil karena memiliki nilai sebesar 29,1464 det/ yang lebih dari standart yang telah ditentukan yaitu sebesar $15 \mathrm{det} / \mathrm{smp}$

5. Peluang Antrian Batas bawah dan Batas atas lebih dari $23 \%$ - $45 \%$ yaitu $52,287 \%$ 105,135\% maka simpang Branggahan Ngadiluwih ini mempunyai tingkat Peluang Antrian lalu lintas yang tinggi.

\section{SARAN}


Untuk menurunkan tingkat nilai hambatan samping yang relatif tinggi perlu pengadaan fasilitas prasarana guna untuk mengurangi hambatan samping tersebut, misalnya memasang rambu dilarang parkir dan berhenti di pendekat simpang yang tidak tersedia bahu untuk parkir demi menurunkan kelas hambatan samping menjadi rendah.

Untuk mengoptimalkan kinerja simpang Branggahan Ngadiluwih ini perlu adanya pemasangan untuk Traffic Light pada persimpangan tersebut supaya memperlancar arus lalu lintas.

Penelitian selanjutnya diperlukan adanya studi mengenai analisa kinerja simpang dengan menggunakan APILL “Alat Pemberi Isyarat Lampu Lalu Lintas”.

\section{UCAPAN TERIMAKASIH}

Dalam penyusunan artikel ini, penulis ucapkan terimakasih kepada dosen pembimbing dan Universitas Kadiri. Penulis berharap agar artikel ini dapat bermanfaat bagi pembaca.

\section{DAFTAR PUSTAKA}

[1] Alhani, K. Erwan, and E. Sulandari, "Analisa Lalu Lintas Terhadap Kapasitas Jalan Di Pinggiran Kota Pontianak (Kasus Jalan Sungai Raya Dalam),” J. Mhs. Tek. Sipil Univ. Tanjungpura, vol. 4, no. 4, pp. 1-7, 2017.

[2] B. A. Harsono, S. Winarto, and Y. C. S, "PERENCANAAN PENINGKATAN JALAN PADA RUAS JALAN PACITAN-NGADIROJO,” Jurmateks, vol. 1, no. 2, pp. 291-302, 2018.

[3] N. Rorong, L. Elisabeth, and J. E. Waani, "Analisa Kinerja Simpang Tidak Bersinyal Di Ruas Jalan S.Parman Dan Di.Panjaitan,” Fak. Tek. Jur. Sipil Univ. Sam Ratulangi Manad., vol. 3, no. 11, pp. 747-758, 2015.

[4] R. H. Lalenoh, T. K. Sendow, and F. Jansen, “Analisa Kapasitas Ruas Jalan Sam Ratulangi Dengan Metode Mkji 1997 Dan Pkji 2014,” J. Sipil Statik, vol. 3, no. 11, pp. 737-746, 2015.

[5] A. Hardianto, "Analisa Pengendalian Manajemen WakANALISA PENGENDALIAN MANAJEMEN WAKTU DAN BIAYA PROYEK PEMBANGUNAN HOTEL DENGAN NETWORK CPM Studi Kasus : Batiqa Hotel Palembang,” Tek. Sipil dan Perenc., vol. 1, no. 1, pp. 1-17, 2015.

[6] P. A. E. Saputra, "EVALUASI KINERJA SIMPANG TIGA BERSINYAL JALAN SUDIRMAN - JALAN TUANKU TAMBUSAI PEKANBARU," J. Linguist., vol. 2, no. 1, pp. 1-13, 2018, doi: 10.18041/2382-3240/saber.2010v5n1.2536.

[7] P. J. Romadhona and R. I. Fauzi, “Analisis Dampak Gang pada Putaran Balik Terhadap 
Kinerja Ruas Jalan Raya Affandi Yogyakarta," J. Teknol. Rekayasa, vol. 3, no. 1, p. 29, 2018, doi: 10.31544/jtera.v3.i1.2018.29-38.

[8] R. Hidayah, A. Ridwan, and Y. C. S. P, "ANALISA PERBANDINGAN MANAJEMEN WAKTU ANTARA PERENCANAAN DAN PELAKSANAAN," Jurmateks, vol. 1, no. 2, pp. 281-290, 2018.

[9] V. Bawangun, T. K. Sendow, and E. Lintong, "Analisis Kinerja Simpang Tak Bersinyal Untuk Simpang Jalan W.R. Supratman Dan Jalan B.W. Lapian Di Kota Manado,” J. Sipil Statik, vol. 3, no. Juni, pp. 422-434, 2015.

[10] A. I. Candra, A. Yusuf, and A. R. F, "Studi Analisis Daya Dukung Pondasi Tiang Pada Pembangunan Gedung Lp3M Universitas Kadiri," J. CIVILA, vol. 3, no. 2, p. 166, 2018, doi: $10.30736 /$ cvl.v3i2.259.

[11] R. Rahman, “Analisa Dampak Lalu Lintas (Studi Kasus: Studi Kemacetan di Jalan Ngagel Madya Surabaya)," SMARTek, vol. 8, no. 4, pp. 317-332, 2010.

[12] M. Atho 'ur Rohman, D. Kartikasari, K. Kunci, and : Kemacetan, "ANALISA KEMACETAN LALU LINTAS PADA PASAR TRADISIONAL DI RUAS JALAN SEKARAN-MADURAN," J. CIVILA, vol. 1, no. 2, pp. 1-6, 2016.

[13] A. D. Limantara, A. I. Candra, and S. W. Mudjanarko, "Manajemen Data Lalu Lintas Kendaraan Berbasis Sistem Internet Cerdas Ujicoba Implementasi Di Laboratorium Universitas Kadiri," 2017.

[14] R. Yuwono, Y. C. Sp, and L. D. K, "STUDY ANALISA VOLUME KENDARAAN PADA SIMPANG BERSINYAL DI PEREMPATAN ALUN ALUN KOTA KEDIRI," Jurmateks, vol. 1, no. 1, pp. 101-111, 2018.

[15] A. Susanto, Y. C. S. P, and S. Winarto, "STUDI PERENCANAAN JEMBATAN CUMPLENG DENGAN METODE PRATEKAN DI KEC. SLAHUNG KABUPATEN PONOROGO,” Jurmateks, vol. 1, no. 2, pp. 172-181, 2018.

[16] C. J. Khisty, Dasar-Dasar Rekayasa Transportasi Edisi Ke-3 Jilid 1. 2005.

[17] E. Nurfadzilah, S. Winarto, and Y. C. SP, "ANALISA JALAN RING ROAD NGAWI STA 3+200 - STA 6+200 KABUPATEN NGAWI PROPINSI JAWA TIMUR," Jurmateks, vol. 1, no. 1, pp. 33-43, 2018.

[18] A. Munawar, Manajemen Lalu Lintas Perkotaan. Jogjakarta: Beta Offset, 2004.

[19] Departemen Pekerjaan Umum, "Manual Kapasitas Jalan Indonesia (MKJI) 1997.” pp. 1$573,1997$.

[20] Alamsyah Alik Ansyori, "Rekayasa Lalu Lintas," Univ. Muhammadiyah Malang, Malang, vol. 53, no. 9, pp. 1689-1699, 2013, doi: 10.1017/CBO9781107415324.004. 